\section{"Conheça e orgulhe-se da Universidade Estadual do Rio Grande do Sul (UERGS) Unidade Três Passos"}

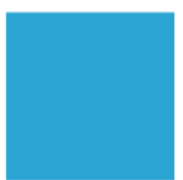

Revista Extensão em Foco
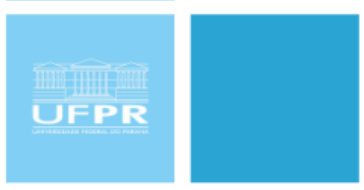

ISSN $2358-7180$ of Rio Grande do Sul (UERGS) Três Passos Unit"

Daniel Kipper ${ }^{1}$, Maiqueli Patrícia Ehrembrink ${ }^{2}$, Luis Henrique Cichelero ${ }^{3}$, Eduardo Canepelle $^{4}$, Danni Maisa da Silva ${ }^{5}$, Divanilde Guerra ${ }^{6}$, Aaron Concha Vasquez Hengles ${ }^{7}$, Mastrângello Enivar Lanzanova ${ }^{8}$, Luciane Sippert Lanzanova9, Marciel Redin ${ }^{10}$, Robson Evaldo Gehlen Bohrer ${ }^{11}$, Ramiro Pereira Bisognin ${ }^{12}$, Eduardo Lorensi de Souza $^{13}$

\author{
RESUMO
}

O objetivo deste projeto foi divulgar e promover a valorização da Universidade Estadual do Rio Grande do Sul (UERGS), Unidade Três Passos/RS. A metodologia de trabalho constou da realização de diversas atividades, durante o ano de 2018, incluindo programas de rádio, atividades de extensão nas escolas, levando aos alunos diversos temas ligado à olericultura e à agroecologia, além da implantação e manutenção de hortas escolares; publicação em jornais e sites de notícias institucional e de circulação regional; manutenção de uma página no Facebook, compartilhando postagens referentes a temas importantes, bem como de imagens ligadas à realidade acadêmica da universidade. Foi promovido o Dia D da Extensão Universitária, com a realização do $1^{\circ}$ Seminário Regional de Agroclimatologia, em parceria com alunos e professores do Curso de Agronomia, que teve uma boa adesão entre os acadêmicos

${ }^{1}$ Acadêmico de Agronomia, Bolsista Proex, Universidade Estadual do Rio Grande do Sul (UERGS), Unidade Três Passos, Três Passos, RS, Brasil. E-mail: daniel-kipper@uergs.edu.br. Orcid: https://orcid.org/0000-0002-0724-0782

${ }^{2}$ Acadêmica de Agronomia, Bolsista Proex, UERGS, Unidade Três Passos, Três Passos, RS, Brasil. Email: maiqueli-ehrembrink@uergs.edu.br. Orcid: https://orcid.org/0000-0001-7159-3825

${ }^{3}$ Acadêmico de Agronomia, Bolsista Iniciação Científica (IC), UERGS, Unidade Três Passos, Três Passos, RS, Brasil. E-mail: luis-cichelero@uergs.edu.br. Orcid: https://orcid.org/0000-0002-9463-8712

${ }^{4}$ Acadêmico de Agronomia, Bolsista Iniciação Científica (IC), UERGS, Unidade Três Passos, Três Passos, RS, Brasil. E-mail: eduardo-canepelle@uergs.edu.br. Orcid: https://orcid.org/0000-0002-4029-5558

${ }^{5}$ Doutora em Ciência do Solo, Docente da UERGS, Unidade Três Passos, Três Passos, RS, Brasil. E-mail: danni-silva@uergs.edu.br. Orcid: https://orcid.org/0000-0002-3600-0462

${ }^{6}$ Doutora em Fitotecnia, Docente da UERGS, Unidade Três Passos, Três Passos, RS, Brasil. E-mail: divanilde-guerra@uergs.edu.br. Orcid: https://orcid.org/0000-0001-5136-2763

${ }^{7}$ Doutor em Educação, Docente da UERGS, Unidade Três Passos, Três Passos, RS, Brasil. E-mail: aaronhengles@uergs.edu.br. Orcid: https://orcid.org/0000-0002-7707-8020

${ }^{8}$ Doutor em Engenharia Agrícola, Docente da UERGS, Unidade Três Passos, Três Passos, RS, Brasil. Email: mastrangello-lanzanova@uergs.edu.br. Orcid: https://orcid.org/0000-0003-2285-1052

${ }^{9}$ Doutora em Letras, Docente da UERGS, Unidade Três Passos, Três Passos, RS, Brasil. E-mail: lucianesippert@uergs.edu.br. Orcid: https://orcid.org/0000-0002-3159-0061

${ }^{10}$ Doutor em Ciência do Solo, Docente da UERGS, Unidade Três Passos, Três Passos, RS, Brasil. E-mail: marciel-redin@uergs.edu.br. Orcid: https://orcid.org/0000-0003-4142-0522

${ }^{11}$ Doutor em Engenharia Civil, Recursos Hídricos e Saneamento Básico, Docente da UERGS, Unidade Três Passos, Três Passos, RS, Brasil. E-mail: robson-bohrer@uergs.edu.br. Orcid: https://orcid.org/00000002-2001-8983

$\frac{12}{12}$ Doutor em Engenharia Civil, Recursos Hídricos e Saneamento Básico, Docente da UERGS, Unidade Três Passos, Três Passos, RS, Brasil. E-mail: ramiro-bisognin@uergs.edu.br. Orcid: https://orcid.org/00000002-1052-3521

${ }^{13}$ Doutor em Ciência do Solo, Docente da UERGS, Unidade Três Passos, Três Passos, RS, Brasil. E-mail: eduardo-souza@uergs.edu.br. Orcid: https://orcid.org/0000-0003-4834-0066 
e comunidade, com o envolvimento de produtores rurais da região, em parceria com a Emater/RS-Ascar e o Instituto Federal Farroupilha, Unidade Santo Augusto; também foi promovido o Dia D da Pesquisa Científica, com o $1^{\circ}$ Salão da Pesquisa UERGS/ETEC, promovido pela UERGS em conjunto com a Escola Técnica Estadual Celeiro (ETEC). A realização destas atividades tiveram grande importância na divulgação da UERGS Unidade Três Passos em toda a Região Celeiro, promovendo maior visibilidade e transparência das atividades/ações realizadas pela universidade, além de possibilitar que esta levasse conhecimentos para a comunidade, contribuindo para o desenvolvimento regional, bem como para a valorização da instituição, podendo torná-la mais atrativa para futuros acadêmicos.

Palavras-chave: Extensão Universitária. Democratização da informação. Pesquisa Científica. Ciências Agrárias.

\section{ABSTRACT}

The objective of this project was to promote and promote the valorization of the State University of Rio Grande do Sul (UERGS), Unit Três Passos / RS. The work methodology consisted of various activities during 2018, including radio programs; extension activities in schools, bringing students various topics related to olericulture and agroecology, as well as the implementation and maintenance of school gardens; publication in local newspapers and websites of news and information about the Unit's activities; maintenance of a Facebook page, where posts were made on important topics, as well as images linked to the University's academic reality. University Extension Day D was promoted by the 1st Regional Agroclimatology Seminar, in partnership with students and teachers of the Agronomy Course, which had a good adhesion between the academics and the community, with the involvement of rural producers in the region, in partnership with Emater/RS-Ascar and the Farroupilha Federal Institute, Santo Augusto Unit; D-Day of Scientific Research was also promoted, through the holding of the 1st UERGS / ETEC Research Salon, promoted by UERGS in conjunction with the Celeiro Technical State School (ETEC). The realization of these activities was of great importance in the dissemination of the UERGS Unit Três Passos throughout the Região Celeiro, in addition to promoting greater visibility and transparency of the activities / actions carried out by the University, towards the community, contributing to the appreciation of UERGS, which could make most attractive to future academics.

Keywords: University Extension. Democratization of information. Scientific research. Agrarian Sciences.

\section{INTRODUÇÃO}

A partir da Idade Moderna a ciência passou a ser o meio de produção do conhecimento e da tecnologia. O conhecimento, a ciência e tecnologia passam a ter um papel fundamental para o indivíduo compreender o mundo em sua extensão e complexidade e tomar decisões de vida (LORDÊLO; PORTO, 2012). A ciência começou a ser vista, como o motor do desenvolvimento, um símbolo do progresso e a universidade, como um centro de produção de conhecimentos úteis e de formação de pessoas capazes de atender aos quesitos de um mundo laboral moldado pelas mesmas ciência e tecnologia (GOERGEN, 1998). “A universidade é uma instituição social com mais de quinhentos anos de história, que desde sua origem possui um caráter inovador, inquietador e revolucionário” (NUNES; SILVA, 2011, p.121).

A Universidade Estadual do Rio Grande do Sul (UERGS), por sua vez, é uma Instituição relativamente recente no cenário da educação superior do país, com apenas 18 
anos de fundação, tendo sido criada pelo Poder Público Estadual sob a forma de Fundação Pública de Direito Privado, Lei n. ${ }^{\circ}$ 11.646, de 10 de julho de 2001 (RIO GRANDE DO SUL, 2001). Na Região Celeiro do Rio Grande do Sul a Universidade está sediada no município de Três Passos, desde o ano de 2006. Embora a Unidade e a própria UERGS tenham uma curta existência até então, muitas ações de integração e em benefício da sociedade já foram realizadas pela instituição, por meio de sua Unidade em Três Passos, com vistas no cumprimento da missão institucional descrita em seu Plano de Desenvolvimento Institucional 2017 - 2022 (UERGS - PDI, 2017 - 2022) de “[...] promoção do desenvolvimento regional sustentável por meio da formação de recursos humanos qualificados, da geração e da difusão de conhecimentos e tecnologias capazes de contribuir para o crescimento econômico, social e cultural das diferentes regiões do Estado" (p.11).

A UERGS está presente em 24 municípios gaúchos, ministrando cursos de graduação e pós-graduação nas três áreas do conhecimento: Ciências Humanas, Ciências Exatas e Engenharias, Ciências da Vida e Meio Ambiente. Deste modo, a universidade possui uma ampla área geográfica de abrangência, estando presente em todas as regiões do Estado e em cidades estratégicas para o desenvolvimento de suas respectivas regiões, buscando com esta distribuição maior dispersão e aplicação dos conhecimentos produzidos em favor do desenvolvimento do Estado. Os cursos oferecidos por todas as unidades são distribuídos conforme a necessidade de cada região, para que assim, as demandas regionais por meio de referendos da comunidade possam ser concretizados por meio do ensino público e de qualidade.

A UERGS Unidade Três Passos está localizada na Região Celeiro, uma região essencialmente agrícola, pois, segundo Barbosa et al. (2010), cerca de 58\% da população vive no meio urbano e $42 \%$ ainda vive no meio rural, tendo a sua economia baseada na agropecuária, com atividades principais na produção leiteira, suinocultura e agricultura. Com vistas ao atendimento de sua vocação regional a UERGS, em Três Passos, tem trabalhado fundamentalmente nas áreas das Ciências Agrárias e Ambientais, dentro das quais, atua na oferta de cursos de graduação, pós-graduação, no desenvolvimento de projetos de pesquisa e extensão. Nesta unidade universitária são oferecidos 2 cursos de graduação em nível de Bacharelado, sendo um em Agronomia e o outro em Gestão Ambiental, além de dois cursos em nível de pós-graduação lato sensu, sendo o Curso de 
Especialização em Gestão e Sustentabilidade Ambiental e o Curso de Especialização em Manejo Sustentável do Solo. O Curso de Agronomia tem tido uma grande adesão e está hoje em sua quinta turma, trabalhando com práticas agrícolas mais sustentáveis aplicadas ao desenvolvimento agropecuário da região. O Curso de Gestão Ambiental se apresenta bem consolidado tendo uma ótima pontuação dentre todas as universidades públicas do Estado, visando o conhecimento e aplicação de manejo sustentável da fauna e flora, sendo esta uma riqueza incomensurável que requer cuidados e manejos específicos.

Tendo em vista a importância regional da universidade, sentiu-se a necessidade de divulgação das atividades realizadas pela instituição, buscando compartilhá-las com a comunidade em geral, a fim de ampliar a visibilidade tanto interna quanto externa. Para Oliveira (2001), os conhecimentos científicos produzidos pela universidade age em três frentes diversas: uma delas é o ensino, permitindo formação profissional, técnica e científica às pessoas; outra é a pesquisa, a base para a busca e descoberta do conhecimento científico, que é realizada pela universidade em busca do conhecimento da realidade e, finalmente, mas não necessariamente em último lugar, considera-se como importante a extensão universitária. Esta se materializa na prestação de serviços e na integração com a sociedade, que pode ser realizada a partir da execução de propostas de extensão universitária como a que está sendo relatada.

Embora várias atividades sejam desenvolvidas pela UERGS Unidade Três Passos se faz necessária a divulgação e o conhecimento da comunidade regional sobre estas atividades desenvolvidas pela universidade e, por se tratar de um órgão público, há também de se destacar a necessidade e a importância da transparência e da visibilidade das ações realizadas, dos projetos de pesquisa e de extensão universitária, bem como de quaisquer outras atividades que envolvam a comunidade acadêmica, já que contam com o aporte de recursos públicos. Para Lordêlo e Porto, (2012), as informações produzidas na universidade, pela ciência, tecnologia e inovação, precisam alcançar a sociedade de alguma forma e, neste cenário, a divulgação científica deve atuar com intensidade. As universidades, geradoras de conhecimento, precisam evidenciar seu caráter de prestação de serviço à comunidade, buscando aproximar ou trazer à opinião pública as pesquisas, discussões e progressos gerados pela ciência e tecnologia, sendo fundamental que se mantenha um processo de comunicação eficiente entre a universidade e seus públicos para difundir com êxito sua produção científica, garantindo assim uma inserção 
verdadeira na sociedade civil (CASTILHO; FACÓ, 2011). Sendo assim, entre os objetivos da universidade deveria estar o planejamento de ações capazes de permitir que a sociedade pudesse conhecê-la mais, além de participar do dia a dia universitário, através da integração em projetos de ensino, pesquisa e extensão, bem como, de poder contribuir com sugestões e/ou discussões sobre "os rumos a seguir" pela universidade, inserindo-a de fato, como parte da região onde está localizada.

Entretanto, a exemplo do que ocorre na grande maioria das instituições de nível superior do Brasil, há pouca divulgação das ações realizadas pela UERGS Unidade Três Passos para a sociedade, por uma série de razões. O que reforça o argumento de Castilho e Facó (2011), de que boa parte dos conhecimentos produzidos na universidade não ultrapassam os muros das instituições e não chegam aos meios de comunicação que poderiam compreendê-las e traduzi-las utilizando uma linguagem que fosse facilmente absorvida por todos.

Sendo assim, o objetivo desta ação de extensão universitária foi contribuir para uma maior divulgação e visibilidade dos conhecimentos acadêmicos e ações desenvolvidas na área das Ciências Agrárias na UERGS Unidade Três Passos, por meio de uma relação intrínseca entre o ensino, a pesquisa e a extensão, visando especialmente a democratização do conhecimento científico. Por meio deste trabalho almejou-se também estabelecer uma maior interação entre a comunidade da Região Celeiro com a UERGS Unidade Três Passos, bem como o fortalecimento desta relação.

\section{METODOLOGIA}

Este projeto de extensão universitária foi elaborado no ano de 2017, submetido e aprovado no Edital PROEX 02/2017 - PROBEX 2018, publicado no site da UERGS (https://proex.uergs.edu.br/programas/probex/probex-2017). Após a aprovação deste, sua execução ocorreu ao longo do ano de 2018, sob a coordenação de professores da UERGS Unidade Três Passos, com a participação de forma integrada dos demais docentes, bem como do corpo técnico de apoio administrativo, acadêmicos voluntários e bolsistas de extensão universitária do Curso de Agronomia e de colaboradores da comunidade em geral. Os objetivos propostos neste projeto foram alcançados por meio da realização de uma série de atividades de divulgação das ações de ensino, pesquisa e extensão, nos diversos meios de comunicação de acesso livre disponíveis aos executores desta proposta. 
O referido projeto teve como ênfase a divulgação das ações na área das Ciências Agrárias, considerando a demanda regional, os cursos oferecidos na unidade e a área de formação dos professores.

A metodologia de trabalho deste projeto envolveu a realização de diversas ações organizadas a partir de reuniões de planejamento, realizadas no início do ano de 2018. A partir de então, foram realizadas atividades práticas de extensão universitária nas escolas da zona urbana e rural do município de Três Passos, por meio das quais, acadêmicos do Curso de Agronomia e professores da UERGS Unidade Três Passos difundiram diversos temas ligados à olericultura e à agroecologia, além de trabalharem na implantação e manutenção de hortas nas escolas. Também foram elaborados e publicados textos e notícias em jornais e sites da Região Celeiro, trazendo informações sobre as atividades cotidianamente realizadas na referida unidade universitária.

As ações de divulgação das atividades de Ciências Agrárias desenvolvidas envolveram ainda a manutenção de uma página no Facebook, desenvolvida em parceria com os acadêmicos da UERGS, na qual foram feitas postagens referentes a temas importantes, além da veiculação de imagens ligadas à realidade acadêmica da universidade. Ademais, foram organizados e promovidos o Dia D da Extensão Universitária e o Dia D da Pesquisa Científica, coordenados pela UERGS Unidade Três Passos, com o apoio de diversos parceiros da comunidade e Região Celeiro.

Após a realização das atividades acima mencionadas, as informações foram organizadas, discutidas e apresentadas à comunidade em geral na forma de relatórios, resumos e deste artigo, em forma de relato de experiência, com vistas à divulgação dos resultados.

\section{RESULTADOS E DISCUSSÃO}

As ações desta proposta de extensão foram desenvolvidas sob a coordenação de professores da UERGS Unidade em Três Passos buscando o envolvimento a comunidade acadêmica e comunidade da Região Celeiro. Foi realizada a organização/manutenção da página do Facebook da UERGS Unidade Três Passos com a perspectiva de atualização das informações com espaços dedicados aos cursos oferecidos pela Unidade, bem como para as ações de pesquisa e extensão (Figuras 1 e 2). 
Figura 1: Publicação no Facebook sobre professor da UERGS Unidade Três Passos sendo homenageado como cidadão do ano no município de Três Passos/RS, 2018.

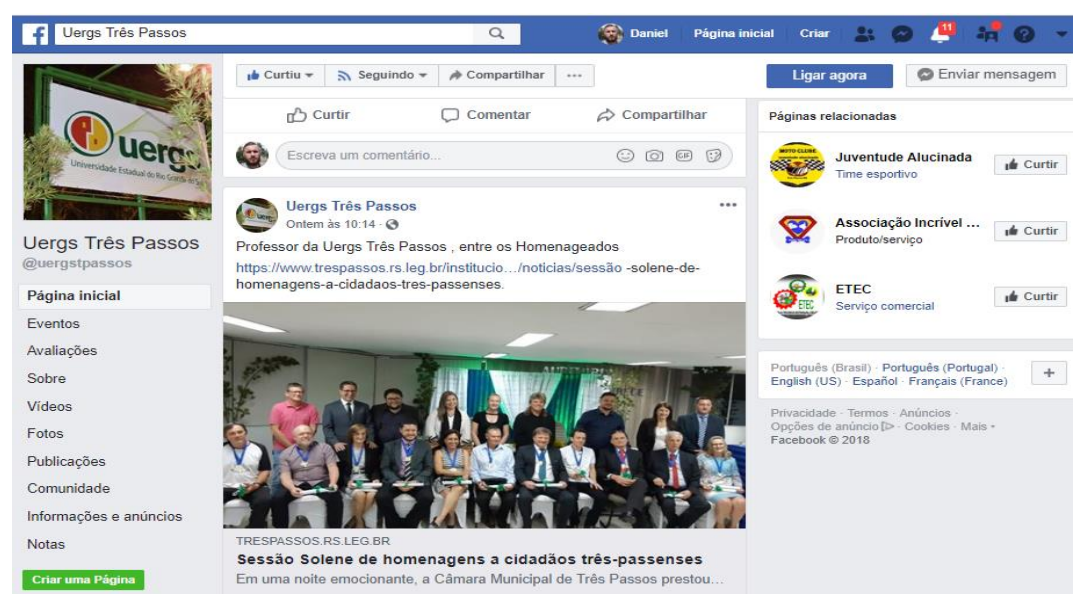

Fonte: Página do Facebook da UERGS Unidade Três Passos (2018).

Figura 2: Publicação no Facebook sobre as atividades de extensão universitária desenvolvidas pela UERGS Unidade Três Passos nas escolas de Três Passos, 2018.

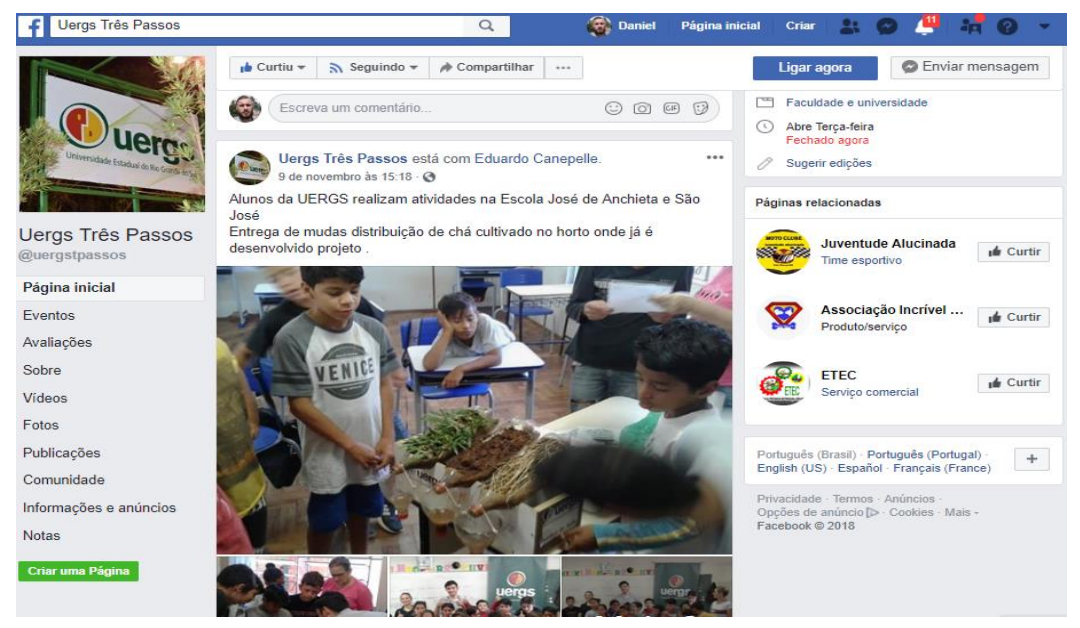

Fonte: Página do Facebook da UERGS Unidade Três Passos (2018).

Na manutenção da página do Facebook, os acadêmicos bolsistas e voluntários do projeto ficaram responsáveis pela obtenção e organização de notícias relacionadas ao andamento das atividades acadêmicas da Unidade, bem como das ações de pesquisa e extensão, a partir do contato com um dos docentes da Unidade. A cada 15 dias, aproximadamente, foram postadas novas informações relacionadas ao andamento das atividades de ensino, pesquisa e extensão coordenadas pelos demais docentes da UERGS Unidade Três Passos, de modo que, qualquer informação relevante relacionada a qualquer outro membro da comunidade acadêmica poderia ser divulgada. Com isso, ocorreu uma 
intensa promoção de divulgação e dos conhecimentos universitários produzidos e discutidos na UERGS para toda a comunidade regional. Segundo Vicente et al. (2015), em se tratando de democratização, a informação é uma necessidade social e por isso a internet e, especialmente, as redes sociais, são a ferramenta com maior potencialidade para facilitar e ampliar a disseminação e o acesso à informação sobre as mais diversas áreas do conhecimento, inclusive para a difusão da ciência. Nesse contexto, segundo Patrício e Gonçalves, (2010), os softwares de redes sociais possuem elevada audiência no Brasil, especialmente o Facebook tornando este uma importante ferramenta que pode ser utilizada como canal de informação para conhecimento público encurtando distâncias entre: instituições de ensino superior, alunos, professores e comunidade.

Com vistas na promoção das ações de ensino realizadas na UERGS Unidade Três Passos, foram realizadas visitas de divulgação dos cursos oferecidos pela Unidade nas escolas do meio rural (escolas do campo) do município de Três Passos, bem como em outras escolas do município e Região. Estas visitas às escolas foram programadas de acordo com a grade de horários e disciplinas ofertadas nos cursos de graduação da Unidade, com o intuito de fortalecer o laço da UERGS com as escolas e difundir dentre outros conhecimentos a agroecologia e práticas agrícolas mais sustentáveis (Figura 3).

Figura 3: Alunos e bolsistas de extensão da UERGS Unidade Três Passos, envolvidos no plantio e manutenção da horta da Escola Estadual Bela Vista, em Três Passos, 2018.

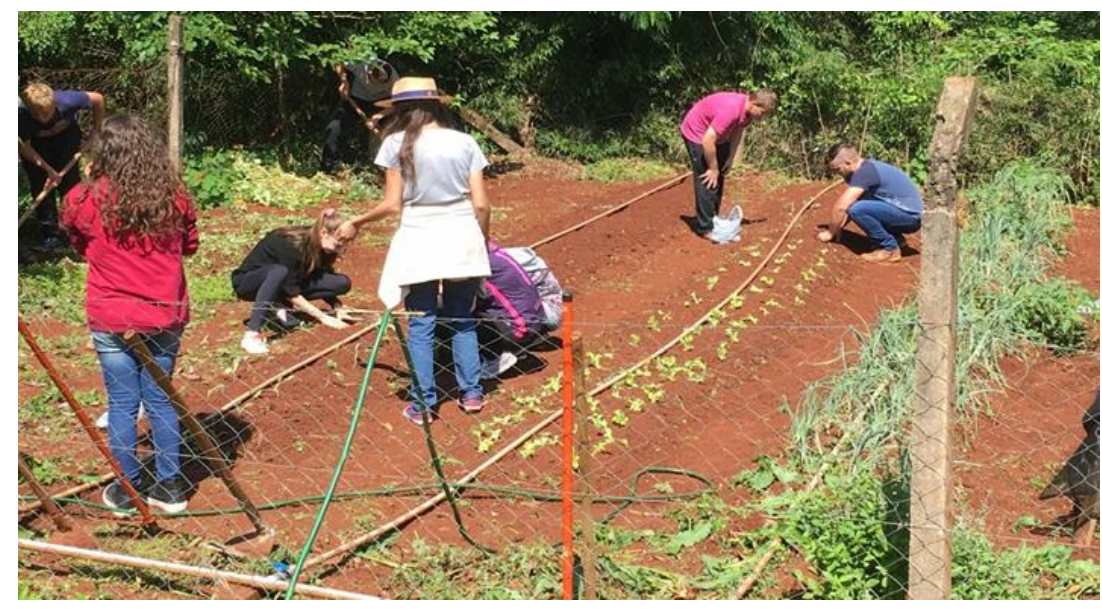

Fonte: Autores (2018).

A escola é um importante espaço para a formação de cidadãos responsáveis e críticos, preparados para discutir sobre questões relacionadas ao meio ambiente e sobre a sociedade, podendo ser as ações relacionadas à agroecologia como consideradas a 
sistematização dos esforços na produção de uma agricultura socialmente justa, economicamente viável e ecologicamente sustentável, além de uma forma de relação com o ambiente, onde todas as formas de vida são protegidas (DE BARROS et al., 2012).

Do mesmo modo, considerando-se que este projeto tinha como objetivo fundamental a divulgação de ações desenvolvidas na área das Ciências Agrárias, diversas ações foram realizadas nas escolas com o intuito de discutir sobre qualidade e vida no solo nas escolas, bem como sobre a importância da cobertura do solo (Figura 4) já que, segundo Muggler et al. (2006), a educação em ciências agrárias com ênfase no solo e demais áreas afins pode construir um efetivo instrumento de educação ambiental levando em consideração a sua importância, apresentando metodologias na formação dos alunos, visando construção de um conhecimento multidisciplinar embasado em práticas agroecológicas e aplicado como ferramenta transformadora da sociedade.

Figura 4: Atividade realizada sobre qualidade, vida no solo e importância da cobertura de solo nas escolas em Três Passos, 2018.

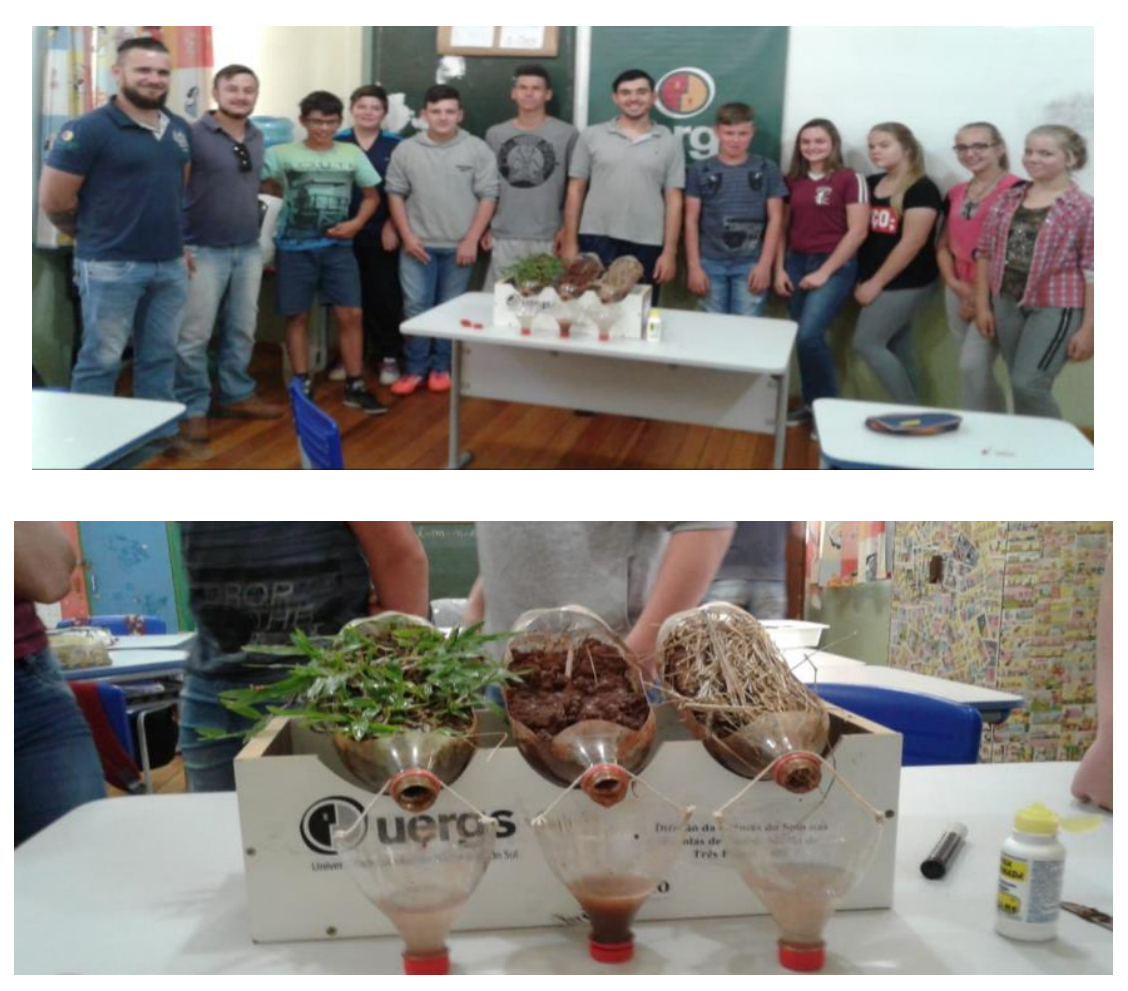

Fonte: Autores (2018). 
Também foram realizados 2 programas de rádio, por meio de contato com as rádios do município, sendo um sobre a indicação de acadêmicos da Unidade ao Prêmio Estadual Jovem Cientista, edição de 2018 da Fundação de Amparo à Pesquisa do Estado do Rio Grande do Sul (FAPERGS) (Figura 5) e outro sobre os sistemas de produção leiteira utilizados na Região Celeiro.

Figura 5: Programa de rádio realizado com a participação de alunos da UERGS Unidade Três Passos indicados ao prêmio estadual Jovem Cientista, promovido pela FAPERGS, em 2018.

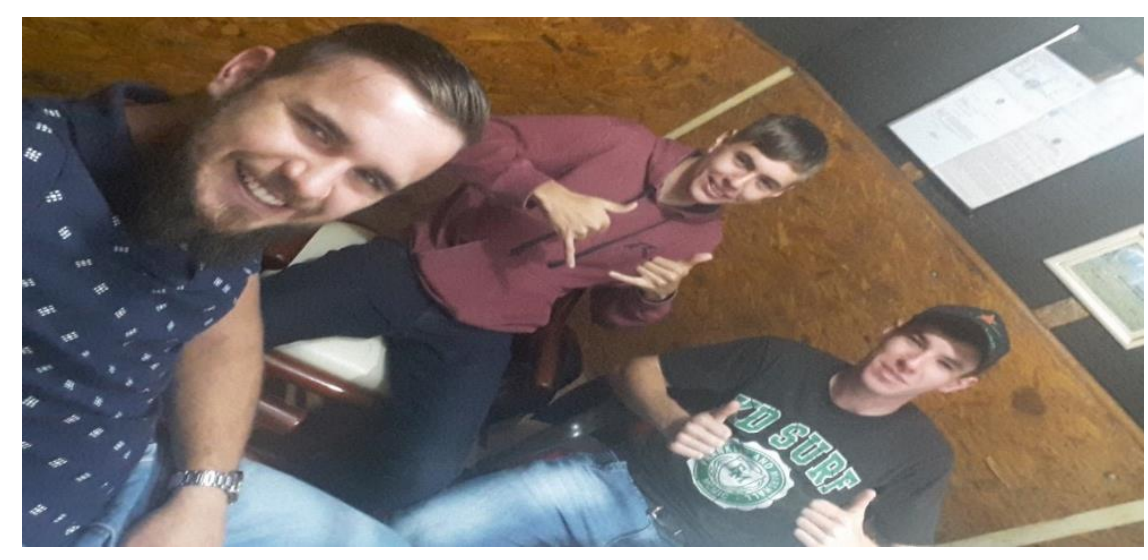

Fonte: Autores (2018).

Os programas de rádio foram apresentados pelos acadêmicos bolsistas do projeto para a divulgação de informações relacionadas à unidade, bem como a divulgação de atividades em andamento. Nos programa de rádio também foram convidados a participar os acadêmicos que tinham disponibilidade para colaborar com a ação ou que tinham envolvimento direto com assuntos em questão, valorizando a presença do aluno na universidade, a escolha pelo curso que realiza e oportunizando a realização prática de uma atividade de comunicação. A utilização de rádio como ferramenta educadora se torna possível devido a sua grande abrangência, ao fácil acesso, e desde que manuseado de maneira apropriada direcionada a um público-alvo, consegue-se obter grande aderência das informações repassadas e conceitos apresentados (KENSKI, 2005).

Ainda, em relação às ações de ensino, trabalhou-se na elaboração de artigos para serem publicados/divulgados em sites e jornais de abrangência regional com divulgações sobre os cursos de graduação e pós-graduação oferecidos pela UERGS Unidade Três Passos, bem como, outras informações pertinentes à questão do ensino, importantes para a Unidade tais como as visitas pelos alunos do $1^{\circ}$ semestre de Agronomia ao Sindicato 
dos Trabalhadores Rurais de Três Passos (STR) (Figura 6 A), realizada na disciplina de Introdução à Agronomia, e sobre o projeto de extensão "Horta é Saúde", desenvolvido pela UERGS Unidade Três Passos (Figura 6 B).

Figura 6: Notícias publicadas em jornal eletrônico sobre atividades de ensino e extensão da UERGS Três Passos, em 2018.

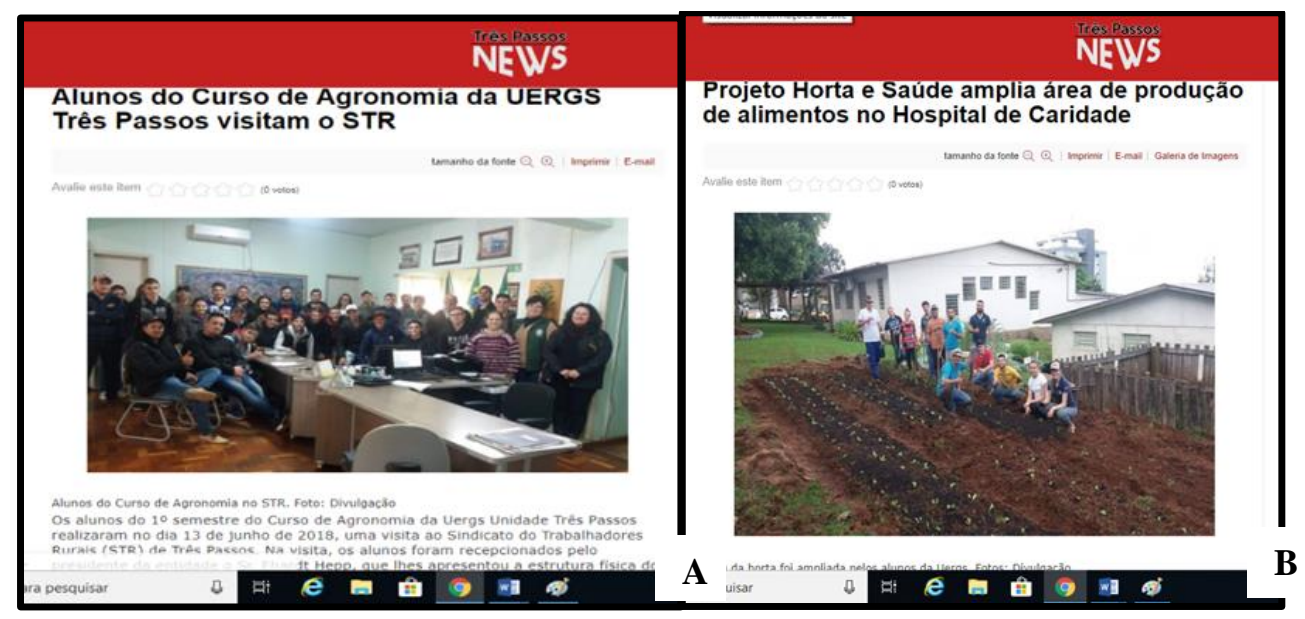

Fonte: Site do Três Passos News (2018).

O jornal impresso também foi utilizado como um meio de divulgação das atividades realizadas pela UERGS Unidade Três Passos durante o ano de 2018 (Figura 7), já que para Ustra et al. (2016), são bastante diversificados os meios que nos permitem acesso aos conteúdos científicos estando dentre os mais comuns exatamente o jornal impresso e falado, além das revistas de divulgação científica, impressas ou disponibilizadas na internet, blogs, rádios e a própria televisão.

Figura 7: Artigo publicado em jornal escrito, elaborado por grupo de acadêmicos do Curso de Agronomia, na disciplina de Comunicação e Extensão, em 2018.

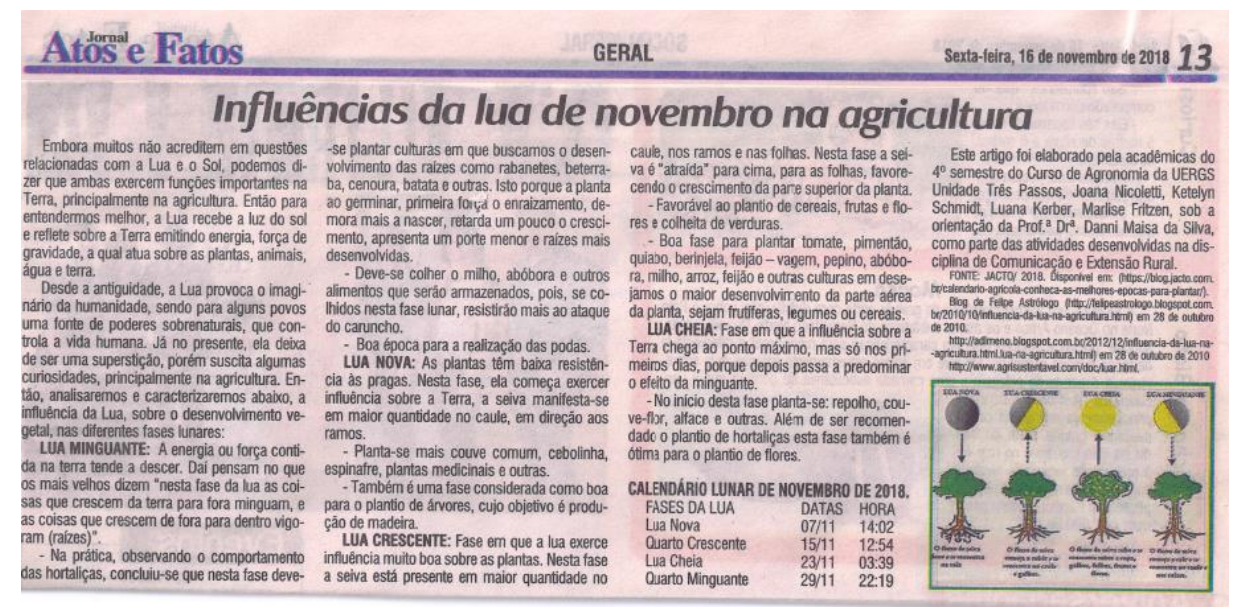


Fonte: Jornal Atos e Fatos (nov. de 2018).

Para a divulgação da importância da extensão na universidade, bem como para oportunizar a experiência na realização de atividades de extensão universitária, foi realizado o Dia D da Extensão Universitária. Com este objetivo foi constituído um grupo de trabalho, representado exclusivamente por acadêmicos do Curso de Agronomia da Unidade e bolsistas de extensão, que promoveu a realização de um seminário voltado a assuntos diretamente relacionados a produção agropecuária da região, denominado ' 1 ' Seminário Regional de Agroclimatologia' (Figura 8), abordando tema de suma importância, o qual necessita conhecimento específico bem aplicado para o bom manejo e produção agrícola.

Figura 8: Folder confeccionado para divulgação do $1^{\circ}$ Seminário de Agroclimatologia, realizado em Três Passos, 2018.

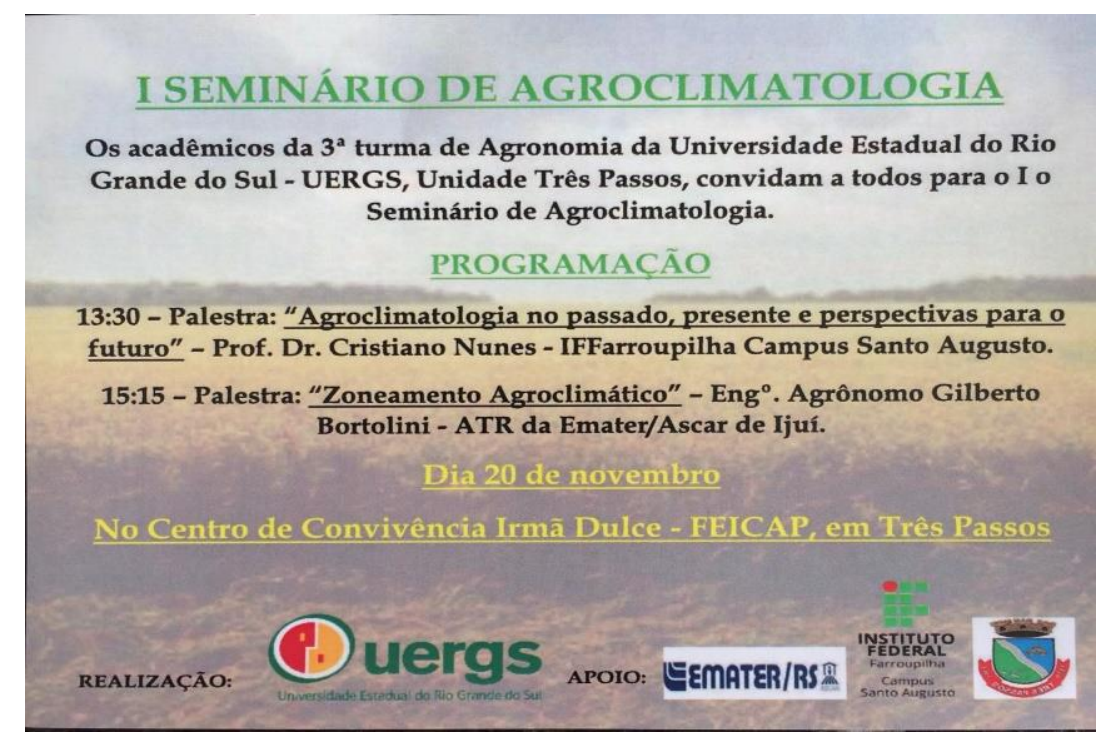

Fonte: Organizadores do evento (2018).

O evento foi coordenado pelo grupo de trabalho formado pelos alunos do Curso de Agronomia e foi realizado em parceria com a Emater/RS-Ascar e o Instituto Federal Farroupilha, Unidade Santo Augusto, tendo expressiva participação dos acadêmicos da Unidade e da comunidade em geral, com o envolvimento de produtores rurais da região. Para Andrade (1998, p. 89), “o seminário constitui uma das técnicas mais eficientes de aprendizagem, quando convenientemente elaborado e apresentado", sendo, portanto, uma importante ferramenta para uso e aplicação na construção de um conhecimento interdisciplinar, tendo em vista o debate e troca de ideias entre os ouvintes e locutores. 
Para a promoção do conhecimento científico foi incentivada a participação do número máximo de acadêmicos na $8^{\mathrm{a}}$ edição do Salão Integrado de Ensino, Pesquisa e Extensão (Siepex) da UERGS, realizado em Cachoeira do Sul/RS (Figura 9).

Figura 9: Artigo de Jornal publicado em 09/11/2018, sobre a participação da delegação da Unidade da UERGS Três Passos, no $8^{\circ}$ Siepex, realizado em Cachoeira do Sul, 2018.

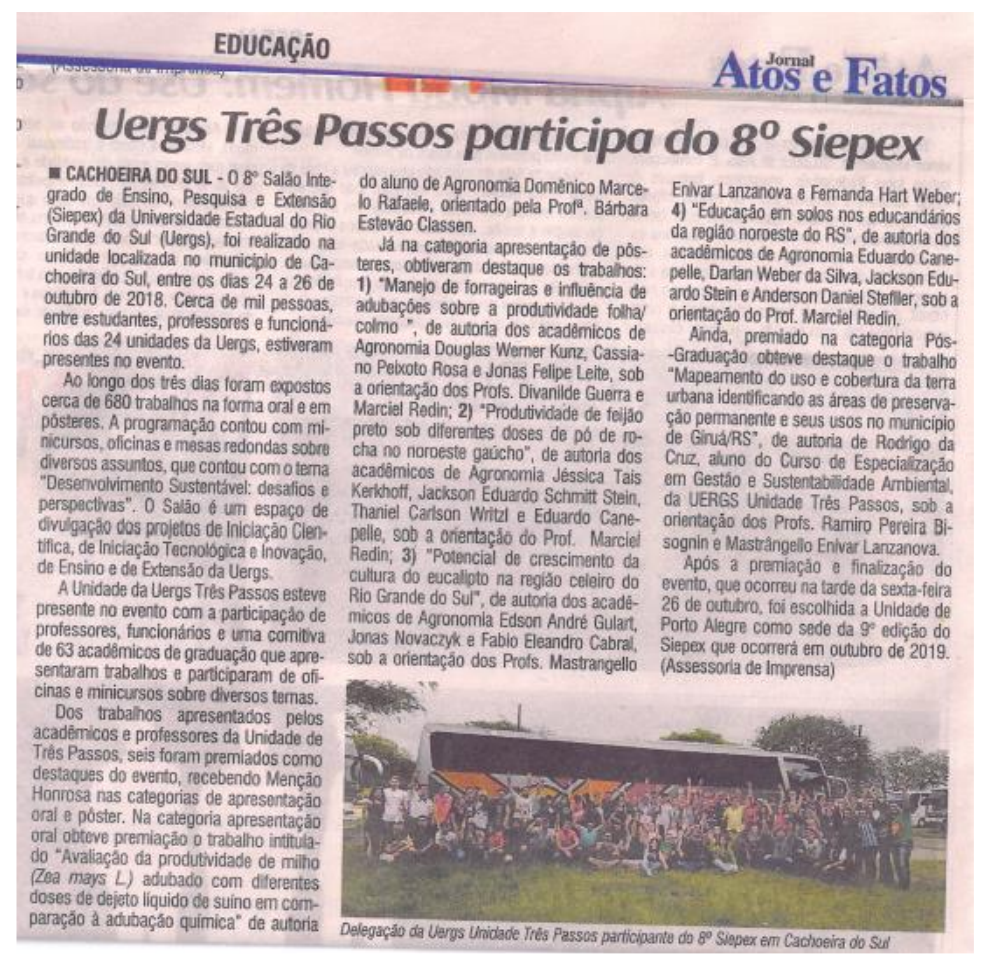

Fonte: Jornal Atos e Fatos (nov. de 2018).

Ainda, com vistas à democratização do conhecimento científico foi promovido o Dia D da Pesquisa na Unidade da UERGS Três Passos, com a realização do " $1^{\circ}$ Salão da Pesquisa UERGS/ETEC", promovido pela UERGS em conjunto com a Escola Técnica Estadual Celeiro (ETEC), de Bom Progresso/RS. O evento foi realizado com o objetivo de fortalecimento da pesquisa científica, divulgação de ações de pesquisa desenvolvidas na Região Celeiro pelas instituições proponentes e fortalecimento das relações institucionais (Figura 10).

Figura 10: Folder de divulgação do $1^{\circ}$ Salão da Pesquisa UERGS/ETEC, realizado em na ETEC, em Bom Progresso/RS, em 2018. 


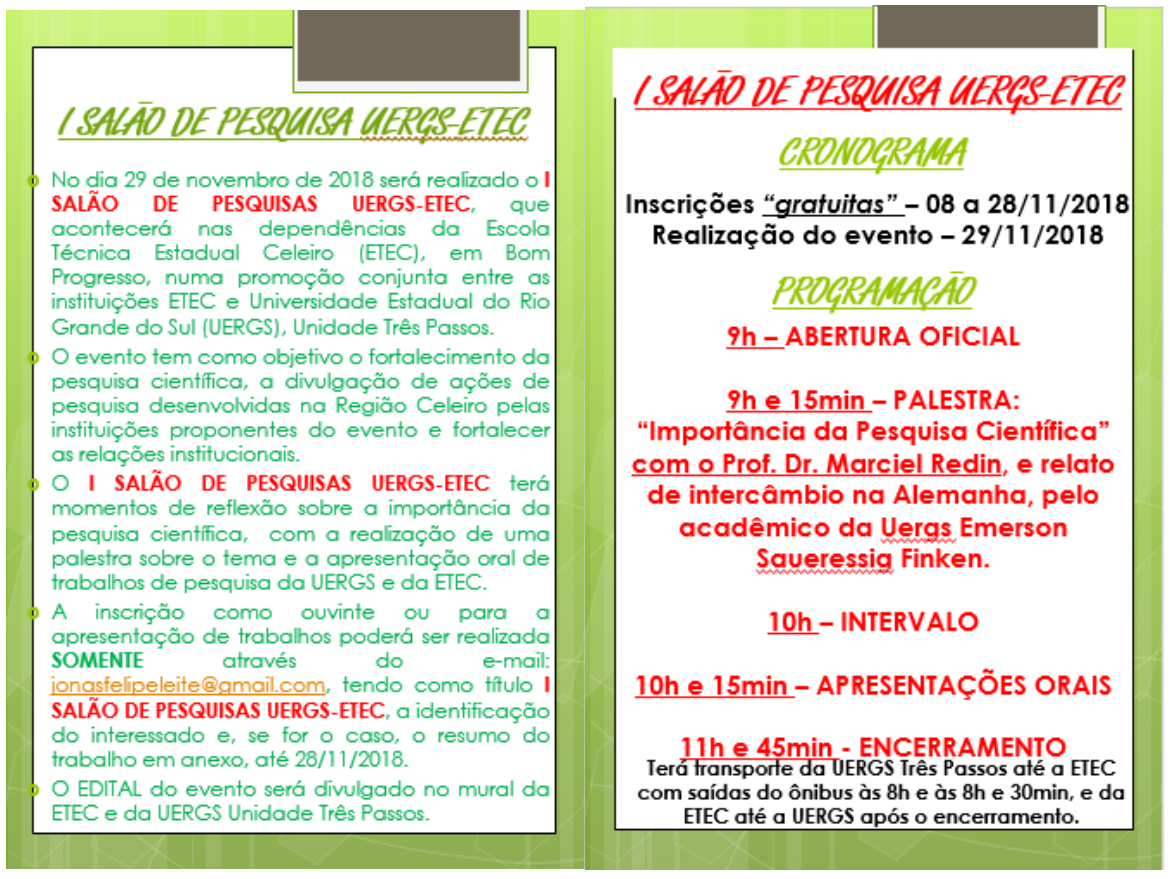

Fonte: Organizadores do evento (2018).

O $1^{\circ}$ Salão da Pesquisa UERGS/ETEC teve momentos de reflexão sobre a importância da pesquisa científica, com a realização de uma palestra sobre o tema e a apresentação oral de trabalhos de pesquisa da UERGS e da ETEC. Para Bueno (2014) a difusão da pesquisa científica e tecnológica tanto favorece o processo de democratização do conhecimento como legitima os investimentos em ciência, tecnologia e inovação, contribuindo para a criação de uma imagem favorável às universidades. Além disso, Queiroz e Becker (2016) ousam concluir ainda que que há uma relação direta entre qualidade acadêmica e divulgação científica. Sendo assim, não basta à universidade produzir conhecimento, é preciso difundi-lo de maneira acessível a toda a população. As ações de difusão da ciência e tecnologia também poderiam contribuir para o conhecimento por parte da população em geral das ações de ensino e mesmo de extensão universitária realizadas pelas instituições de ensino superior e contribuir sobremaneira para a valorização das universidades e sua maior interação com a sociedade.

As atividades apresentadas neste artigo foram algumas das ações desenvolvidas durante a execução do projeto de extensão universitária "Conheça e Orgulhe-se da Universidade Estadual do Rio Grande do Sul em Três Passos", que visivelmente contribuiu para divulgar e promover a valorização da UERGS Unidade Três Passos/RS, permitindo que a comunidade três-passense e regional conhecessem o que a universidade faz, quais as atividades que desenvolve, quais e como os conhecimentos são produzidos. 
Ademais, merece destaque a importância desta ação ao possibilitar que a UERGS levasse conhecimentos da universidade para a comunidade, contribuindo de forma efetiva para o desenvolvimento regional, atendendo uma das premissas básicas da locação das unidades da UERGS nos municípios e regiões do interior do Estado do RS, além de ser este o papel fundamental das ações de extensão universitárias.

Para finalizar, é de suma importância registrar que todas as ações deste projeto foram realizadas em conjunto e com a participação de representantes e das entidades parceiras da instituição, tais como as Secretarias Municipais da Agricultura, do Meio Ambiente e da Saúde do Município de Três Passos, a Prefeitura Municipal de Três Passos, a Câmara Municipal de Vereadores de Três Passos, a Escola Técnica Estadual Celeiro (ETEC), 21 a Coordenadoria Regional da Educação (CRE), Escolas Municipais e Estaduais de Três Passos, Hospital de Caridade de Três Passos, Conselhos Municipais de Três Passos, Sindicato dos Trabalhadores Rurais, Associação dos Municípios da Região Celeiro (AMUCELEIRO) e prefeituras da Região Celeiro, dentre outras.

\section{CONSIDERAÇÕES FINAIS}

A execução desta proposta de extensão universitária, utilizada como ferramenta para divulgação de cursos, conhecimentos científicos, atividades e informações oriundas da UERGS Unidade Três Passos, mostrou-se bastante eficiente como uma ferramenta de democratização da informação universitária, tendo contribuído, sobremaneira para a divulgação, promoção e valorização não apenas da unidade, mas da universidade de modo geral.

Todas as atividades relatadas foram realizadas com grande engajamento dos envolvidos demonstrando a importância e o interesse da comunidade acadêmica e do público em geral pelas informações que permeiam a universidade, permitindo que a comunidade três-passense e regional conhecessem melhor a UERGS e que esta levasse conhecimentos da universidade para a comunidade, contribuindo de forma efetiva para o desenvolvimento regional.

Por fim, a execução deste projeto foi de grande importância para a divulgação da UERGS em toda a Região Celeiro, além de promover maior visibilidade e transparência das atividades/ações realizadas pela universidade perante a comunidade 
interna e externa, contribuindo para a valorização da instituição, tornando-a, de certo modo, mais atrativa para futuros acadêmicos, estreitando-se os laços com diferentes parceiros e promovendo uma maior identificação da comunidade acadêmica com a instituição.

\section{AGRADECIMENTOS}

À Pró-reitoria de Extensão da UERGS (PROEX/UERGS) pela concessão da bolsa de extensão universitária, obtida no Edital PROEX 2017/PROBEX 2018.

\section{REFERÊNCIAS}

ANDRADE, M. A elaboração de seminários: Introdução à metodologia do trabalho científico. 3 ed. São Paulo: Atlas. 1998.

BARBOSA, F. R., RASIA, P. C., BADO, S. L. R.; MACHADO, T. F (org.). Plano Estratégico de Desenvolvimento da Região Celeiro - RS. Ed. Unijuí, 76p. 2010.

BUENO, W. C. Divulgação da Produção Científica no Brasil: A Visibilidade da Pesquisa nos Portais das Universidades Brasileiras. Revista Ação Midiática - Estudos em Comunicação, Sociedade e Cultura, n. 7, 2014.

CASTILHO, A.; FACÓ, J. F. B. A Divulgação Científica na Universidade Pública: Case Universidade Federal do ABC. XXXIV Congresso Brasileiro de Ciências da Comunicação. Recife, PE-2 a 6 de setembro de 2011.

DE BARROS, L. C.; DAMBROS, G.; MACHADO, D. T. M. Agroecologia na escola: desenvolvimento de atividades agroecológicas na Rede Pública de Ensino de Cachoeira do Sul/RS. Revista Monografias Ambientais, v. 5, n. 5, p. 1032-1037, 2012.

GOERGEN, P. Ciência, sociedade e universidade. Educ. Soc., Campinas, v. 19, n. 63, p. 53-79, ago. 1998.

KENSKI, V. Gestão e uso das mídias em projetos de educação a distância. Revista e-curriculum, v. 1, n. 1, 2005.

LORDÊLO, F. S.; PORTO, C. M. Divulgação científica e cultura científica: Conceito e aplicabilidade. Rev. Ciênc. Ext., v.8, n.1, p. 27, 2012. 
MUGGLER, C; SOBRINHO, F; MACHADO, V. Educação em solos: princípios, teoria e métodos. Revista Brasileira de Ciência do Solo, v. 30, n. 4, 2006.

NUNES, A. L. P. F.; SILVA, M. B. C. A extensão universitária no ensino superior e a sociedade. Mal-Estar e Sociedade, n. 7, p. 119-133, 2011.

OLIVEIRA, J. A. A Universidade e a formação para a qualidade de vida. Da Vici. Textos Acadêmicos. Natal: UFRN/Diário de Natal, 28 abr. 2001. p.3.

PATRÍCIO, M; GONÇALVES, V. Facebook: rede social educativa? I Encontro Internacional TIC e Educação, p. 593-598, 2010.

QUEIROZ, G. B. R.; BECKER, V. Jornalismo e divulgação científicos nas universidades brasileiras: análise de estratégias para facilitar o acesso à C\&T. Brazilian Journalism Research, v. 12, n. 3, p. 178-197, 2016.

RIO GRANDE DO SUL. Lei n 11.646 de 10 de Julho de 2001. Autoriza o Poder Executivo a criar a Universidade Estadual do Rio Grande do Sul - UERGS e dá outras providências. Diário Oficial do Estado do Rio Grande do Sul, Porto Alegre, RS, 11 jul. 2001.

UERGS - UNIVERSIDADE ESTADUAL DO RIO GRANDE DO SUL. Plano Desenvolvimento Institucional (PDI 2017 -2022). Porto Alegre: 2017.

USTRA, S. R. V.; LOPES, J. P.; TAVARES, O. A.; BARBOSA, T. F.; USTRA, M. K. Contribuições da divulgação científica na mídia local para a leitura do cotidiano. CATAVENTOS-Revista de Extensão da Universidade de Cruz Alta, v. 7, n. 1, p. 191203, 2016.

VICENTE, N. I., CORRÊA, E. C. D., SENA, T. A divulgação científica em redes sociais na internet: proposta de metodologia de análise etnográfica. (Comunicação Oral). XVI Encontro Nacional de Pesquisa em Ciência da Informação (XVI ENANCIB). GT 7 - Produção e Comunicação da Informação em Ciência, Tecnologia \& Inovação. João Pessoa, PB, 2015.2 Disponível em: http://www.ufpb.br/evento/index.php/enancib2015/enancib2015/paper/viewFile/2853/1 160. Acesso em: 02 jan. 2020. 
DOI: http://dx.doi.org/10.5380/ef.v0i20

Recebido em: 16 de janeiro de 2020.

Aceito em: 17 de junho de 2020. 